\title{
ENSINO DE LÍNGUA PORTUGUESA POR MEIO DO DESENVOLVIMENTO DE UM JOGO DIDÁTICO: UMA PROPOSTA PARA O ENSINO DE PRODUÇÃO DE TEXTOS ORAIS E ESCRITOS
}

\author{
Maria Clara Maciel de Araújo Ribeiro* \\ Awdrey Dorásio de Souza Oliveira**
}

\begin{abstract}
Resumo: Esta pesquisa foi desenvolvida em um Programa de Mestrado Profissional em Letras e objetivou elaborar um protótipo de material didático inovador para o ensino de língua portuguesa nos anos finais do Ensino Fundamental. Objetivou-se, especificamente, produzir um jogo didático que promovesse a atividade de expressão oral e escrita de alunos da rede pública de ensino. O protótipo do jogo foi elaborado por meio de uma pesquisa qualitativa que investigou as contribuições didáticas do jogo em ambiente escolar, elaborando situações de comunicação capazes de demandar atividades de expressão pertinentes às vivências dos estudantes. Os resultados indicam que o produto em questão apresenta potencialidades didáticas para o ensino de português, sendo considerado um instrumento inovador para o Ensino Fundamental.
\end{abstract}

Palavras-chave: Jogo didático. Gêneros textuais/discursivos. Práticas sociais. Ensino de português.

\begin{abstract}
This research was aimed to elaborate a prototype of innovative didactic material for Portuguese language teaching in the final years of Elementary School. It was developed in a Master's Program in Letters. Specifically, it was aimed to produce a didactic game that promotes the activity of oral and written expression of students of public schools. The game prototype was elaborated through a qualitative research that investigates didactic contributions of the game in the school environment, through elaboration of communication situations capable of demanding activities of expression pertinent to the experiences of the students. The results indicate that the product in question presents didactic potentialities as a tool for Portuguese teaching at Elementary School level.
\end{abstract}

Keywords: Didactic game. Genres. Social practices. Teaching Portuguese.

\section{Introdução}

Atualmente, um dos grandes desafios do ensino de português na Educação Básica é ampliar e aprofundar a convivência dos estudantes com gêneros variados, ressignificando-os a partir das práticas sociais que os fundamentam, que são altamente diversificadas, dinâmicas e quase inesgotáveis. No bojo desse desafio, surgem demandas complementares, como a necessidade de se superar a utilização do livro como recurso didático totalizador, em sala de aula, assim como a urgência de se alterar certa tradição que ainda privilegia, nos estudos de gêneros textuais/discursivos, o ensino conceitual-formal, em detrimento do estudo pragmático-operatório de sua funcionalidade em contexto social. Tais desafios fazem surgir outros, em efeito cascata: há que se superar a baixa entrada de gêneros orais na escola, e também a de gêneros informais, ainda que escritos, ampliando o debate à discussão do problema da artificialização do texto na escola, pois a rigor se observa, na escola, a transformação de gêneros cotidianos em gêneros puramente escolarizados, extirpados de suas condições de produção e circulação.

Partindo da discussão acima e pensando em modos de se contribuir para a superação desse cenário, questiona-se: o que pode ser feito para tornar as aulas de português no Ensino Fundamental II mais dinâmicas e vinculadas às situações de produção que demandam, na vida

\footnotetext{
* Doutora em Linguística pela UFMG e professora do Mestrado Profissional em Letras da Universidade Estadual de Montes Claros. Endereço eletrônico: mclaramaciel@hotmail.com

** Mestre em Letras pela Universidade Estadual de Montes Claros e professora da Educação Básica da rede pública de Minas Gerais. Endereço eletrônico: awdrey@oi.com.br
} 
social, atividades de expressão e compreensão? A nosso ver, uma resposta possível aponta para a introdução de jogos na escola. Embora eles não sejam incomuns, nas aulas de língua eles costumam se limitar à abordagem gramatical, não extrapolando o nível da sentença. Assim, a nossa proposta envolve a elaboração de um jogo didático para se focalizar o ensino por meio de gêneros.

Por essa via, consideramos importante oferecer uma ferramenta didática que oportunize a alunos e professores produzirem textos: a) a partir de uma demanda social definida por uma situação de comunicação apresentada; b) com interlocutores e intenções prédeterminadas; c) a partir de uma variedade de esferas de comunicação; d) a partir da indicação de predominância tipológica; e) por meio de situações de comunicação próximas daquelas vivenciadas por estudantes de escola pública; f) a partir de elementos de ludicidade, competitividade, interatividade, descontração e motivação. A partir dessas questões, deu-se então início à elaboração de um jogo didático para o ensino de gêneros textuais/discursivos, como relataremos neste estudo.

Para o desenvolvimento do recurso didático, levamos em consideração que a escola precisa propiciar ao estudante uma efetiva apropriação dos gêneros e, para isso, o professor precisa ter a possibilidade de incluir, em sua estratégia de ensino, além do livro didático, outros instrumentos de aprendizagem que contribuam para a inclusão de seus alunos na cultura da produção escrita. Foi justamente esta a proposta da pesquisa em questão: desenvolver um jogo que poderá ser utilizado pelo professor como recurso didático, com a finalidade de contribuir para a apropriação de gêneros textuais/discursivos na escola.

Nessa perspectiva, a produção do jogo buscou aproximar a aprendizagem adquirida no decorrer da ação, da adquirida em um meio institucional, por meio da produção de um jogo didático que simula situações de interações linguísticas cotidianas visando à produção de gêneros orais e escritos a partir de uma abordagem predominantemente funcional. Assim, a proposta é a de que os alunos se engajem na atividade didática sem se darem conta - ou pelo menos não de maneira enfática - dos processos de ensino-aprendizagem que a fundamentam. Nesta proposta, esperamos que a produção e recepção de gêneros em situação de jogo em ambiente escolar possam vir a contribuir com processos de ensino de língua e que busquem pertinência entre o que e como os alunos preferem aprender e o que os professores precisam ensinar. Este artigo apresentará, portanto, as concepções teóricas que fundamentaram a produção do jogo, bem como o processo de sua concepção criativa e dinâmica participativa.

\section{Concepções teóricas}

Para esta discussão, vamos nos pautar na concepção de gênero proposta por Bakhtin (2003) e pela definição de esferas de circulação proposta pelo mesmo autor, acrescidas das contribuições fundamentais de Marcuschi (2008), Schneuwly e Dolz (2004) e Dolz, Gagnon e Decândio (2010).

Bakhtin (2003) concebe a linguagem como fenômeno ideológico, histórico e social, definindo o discurso (e sua composição por enunciado) como uma unidade de comunicação verbal sempre modificável (tanto pelas necessidades comunicativas quanto pelo decorrer da história). Nesta concepção, toda comunicação se materializa em gêneros textuais/discursivos que são realizações linguísticas concretas construídas historicamente pelo sujeito.

Por meio da materialização da linguagem é que podemos convergir todos os aspectos presentes nas relações estabelecidas entre os interlocutores em atividade prática comunicativa e assim produzir gêneros de forma mais dinâmica e significativa, ou seja, é por meio dos enunciados concretos que a língua penetra na vida e vice-versa (BAKHTIN 2003, p. 282). 
Bakhtin (2003) ainda afirma que os gêneros que circulam na sociedade são infinitos e variados e que estão sempre carregados por outros enunciados que já vimos ou ouvimos em algum momento de nossas vidas. Por isso, não convém que o trabalho com gênero, em sala de aula, seja feito de forma descontextualizada e estanque, uma vez que gêneros surgem a partir da necessidade humana de se comunicar e devido à interação entre o que já se sabe e o que se pretende expressar.

Dependendo de nossa inserção na sociedade ou sobre o que pretendemos falar, atuamos através de gêneros textuais/discursivos já sedimentados pela sociedade. Embora sedimentados, tais gêneros podem variar de acordo com o tempo, o modo de utilização e as intenções dos interlocutores.

É por meio dos gêneros que podemos vislumbrar as mais variadas esferas de circulação ${ }^{1}$ que, segundo Bakhtin (2003), constituem essencialmente setores da atividade humana que indicam instâncias de produção discursiva, originando o chamado discurso jurídico, discurso jornalístico, discurso religioso, discurso pedagógico, entre outros. Assim, de um domínio não resulta apenas um gênero, mas um conjunto de gêneros que são categoricamente engendrados naquela esfera de circulação. O domínio jurídico, por exemplo, origina os gêneros sentença, contrato, lei, súmula, acórdão, entre outros.

Marcuschi (2008, p. 194) define que "os domínios discursivos produzem modelos de ação comunicativa que se estabilizam e se transmitem de geração para geração com propósitos e efeitos definidos e claros". E prossegue dizendo que tais domínios acarretam ainda "formas de ação, reflexão e avaliação social que determinam os formatos textuais" (p. 194). Domínios, portanto, são fundamentais para o estabelecimento de características genéricas.

No jogo, as situações de comunicação que demandam atividades de expressão são organizadas a partir de domínios específicos, a saber, de seis deles: esferas comercial, interpessoal, ficcional, lazer, instrucional, publicitária. Entende-se que levar os alunos a vislumbrarem as regularidades dos domínios é altamente salutar para a compreensão das ações sociais desempenhadas por gêneros. Os gêneros engendrados em cada domínio serão ainda materializados em textos com predominância tipológica relacionadas à sua finalidade: se narrar, argumentar, expor, instruir ou descrever. A partir daí, prevê-se uma cena tipológica típica para cada gênero, embora se admita que esse padrão pode ser facilmente quebrado, dada às intenções particulares a cada ato de fala ou às mesclas de gêneros que tanto caracterizam a contemporaneidade.

Assim, no jogo, os alunos receberão instruções indiretas sobre a tipologia predominante e preferencial a ser desenvolvida em cada situação de comunicação, com a intenção de levá-los à eficiência máxima tanto da compreensão da situação quanto da atividade a ser produzida. Logo, a partir da tríade domínios discursivos, gêneros textuais/discursivos e tipologia textual espera-se oferecer aos estudantes, por meio do jogo, um desenho claro tanto das características sociais que estão na base dos gêneros quanto de algumas regularidades linguísticas que os constituem.

Tal reflexão constitui uma tentativa de mostrar que as condições de produção do texto e a seus propósitos comunicativos determinam a peça a ser produzida. Por isso, torna-se desejável que, no ambiente escolar, as práticas de produção de textos possam ser similares àquelas que acontecem "além dos muros da escola", como indicam Dolz; Gagnon e Decândio (2010, p. 13).

\footnotetext{
1 Neste estudo, intercambiamos as expressões "esferas de circulação" e "domínio discursivo", utilizadas respectivamente por Bakhtin e Marcuschi, pelo fato de ambas de referirem ao mesmo objeto.
} 


\subsection{Jogos na escola}

Kishimoto (1998, p.19), ao conceituar jogo educativo, diz haver divergências nos significados atuais, pois o jogo pode exercer diferentes funções: apenas lúdica (para entretenimento), quando não possuir objetivos pedagógicos explícitos, ou apenas pedagógica (para ensinar), quando for planejado com o objetivo de atingir conteúdos específicos e para ser utilizado somente em âmbito escolar. Ele afirma que o equilíbrio entre as duas funções é que determina o caráter educativo do jogo.

Assim, jogos feitos apenas para entretenimento, com fins comerciais, podem se tornar jogos educativos, da mesma maneira que jogos planejados para atingir objetivos pedagógicos podem se tornar apenas lúdicos. Nessa perspectiva, muitas dúvidas costumam existir quando os educadores procuram associar o jogo à educação e uma delas é saber diferenciar o jogo educativo do material pedagógico. Kishimoto (1998, p. 22) afirma, contudo, de maneira quase radical, que "esta polêmica em torno da utilização pedagógica do jogo, deixa de existir quando se respeita a sua natureza, uma vez que se pode dizer que todo jogo é educativo em sua essência, já que em qualquer tipo de jogo, a criança sempre se educa".

Na escola, o jogo surge, portanto, como elemento motivacional que ensina disciplina, estratégia, cumprimento de regras e competição a estudantes que por vezes assistem a aulas desinteressadamente.

Macedo, Petty e Passos (2005) afirmam que em suas práticas escolares puderam perceber que nem sempre é possível propor atividades que motivem os alunos e que sejam centradas em suas realidades. Para os autores

[...] muitas vezes a dificuldade de lidar com algumas situações do contexto escolar é consequência de propostas que não fazem sentido para as crianças, ou seja, elas não conseguem ver mais longe do que o aqui-agora e não se sentem mobilizadas para realizar tarefas, o que as impede de produzir bons resultados. Em outras palavras, geralmente consideram desnecessário aprender algo cuja aplicação não é imediata. (MACEDO; PETTY; PASSOS, 2005, p. 28).

Desta forma, defendemos que abrir espaços para atividades lúdicas como instrumento de ensino possibilitam aos alunos construir e não apenas adquirir conhecimentos. Ao privilegiar a interação entre os alunos em eventos comunicativos diversos, dentro de um ambiente escolar motivador, o professor terá a possibilidade de integrar as atividades de produção de texto com o cotidiano, fazendo os alunos reconhecerem o uso social da língua, permitindo que os mesmos aprendam a produzir textos orais e escritos de forma situada e motivada. Isso implica em práticas pedagógicas que criem situações significativas que estimulem os alunos.

Na tentativa de refletir sobre a necessidade de mudanças da prática docente, Macedo, Petty e Passos (2005) propõem que trabalhar com jogos pode contribuir significativamente para o processo ensino-aprendizagem, pois possibilita uma relação mais harmoniosa entre alunos e professores, transformando o ensinar e aprender numa atividade colaborativa e divertida. Segundo eles, as regras dos jogos regulam as ações, determinando o que pode ou não pode ser feito, com vistas a definir claramente os objetivos, dando condições iguais a cada um dos participantes de ensinar e aprender o que foi proposto pelo jogo, de modo que jogar se torna um brincar regulado. 
Assim sendo, os jogos podem se constituir em um excelente instrumento para levar os alunos a se envolverem em projetos que representem situações significativas, além de um grande aliado para o desenvolvimento cognitivo quando permeiam atividades que promovam o estímulo à atenção, concentração, interatividade, seletividade de estímulos, capacidade de abstração, planejamento, controle mental, autocontrole e memória operacional (RAMOS, 2013 , p. 25). Portanto, o trabalho com jogos em ambiente escolar pode dar subsídios ou suportes para um melhor desempenho no processo de desenvolvimento do ensinoaprendizagem.

Autores como Almeida (2003) incentivam a utilização de jogos de fácil acesso, que têm baixo custo e são de fácil confecção, que também podem ser adaptados a vários níveis de ensino. $\mathrm{O}$ autor sugere jogos como dominós (de letras, sílabas ou palavras); bingos (de letras, sílabas ou palavras); jogos da memória (de letras, sílabas ou palavras); forca, palavras cruzadas, caça-palavras, diagramas, crucigramas, criptogramas, baralho silábico e quebracabeças. Trata-se de jogos que podem ser usados como estratégias que facilitam "a integração dos conteúdos a vida cotidiana dos alunos, sem que estes se tornem enfadonhos e distancie o aluno da escola" (ALMEIDA, 2007, p. 89).

Contudo, chamamos a atenção para o fato dos jogos de língua portuguesa existentes envolverem principalmente a aprendizagem de conteúdos gramaticais, não ultrapassando o nível da palavra ou da sentença. A partir disso, o jogo em discussão privilegiou o texto como unidade de ensino, pois entende-se que a comunicação humana não se dá a partir de um emaranhado de palavras, mas sim de uma situação de comunicação específica que demanda intencionalidades e objetivos, aspectos que garantem que um fio de sentido constitua palavras em textos.

\section{O processo de produção do jogo didático}

\subsection{Resumo do jogo}

Esta pesquisa elaborou um jogo didático que oportuniza aos alunos do Ensino Fundamental II ( $6^{\circ}$ ao $9^{\circ}$ anos) a produção de textos orais e escritos na escola. Para tanto, teve-se como modelo os jogos de interação sem tabuleiro. Para minimizar o que poderia ser uma falta, propôs-se uma tabela de acompanhamento das rodadas, a ser afixada na lousa da escola. Este quadro apresenta ainda uma correspondência entre números, ilustrações e domínios discursivos, de um lado, e entre cores e tipologias, do outro ${ }^{2}$.

Trata-se de um jogo em que o estudante gira uma roleta, contendo distintos domínios discursivos, a partir dos quais escolherá uma carta que descreverá dada situação de comunicação, que demanda aos sujeitos uma atividade de expressão oral ou escrita. As equipes terão um tempo determinado para a realização da atividade e, após isso, apresentarão o texto à turma. Além das equipes jogadoras, o jogo demanda a formação de uma equipe de avaliação, que julgará a adequação do produto à situação apresentada. Para tanto, a equipe avaliadora levantará placas com emoticons contendo expressões neutras (não atendeu à situação), com meio sorriso (atendeu parcialmente a situação de comunicação) ou com sorriso aberto (atendeu plenamente à situação de comunicação). Vence o jogo a equipe que melhor se

\footnotetext{
${ }^{2}$ A roleta contém números correspondentes a domínios. Ao sortear um número, o aluno verifica no quadro a que domínio o número corresponde e pega o cartão-comando correspondente. Esses cartões são ilustrados com figuras indicativas do domínio, de um lado, e textos que indicam a situação de comunicação a ser desempenhada, do outro. Cada cartão recebe, ao fundo do texto, uma cor indicativa da tipologia preferencial.
} 
sair na soma das rodadas. A seguir, apresentaremos, passo a passo, tanto o jogo quanto os seus componentes e o seu processo de produção.

\subsection{Escolhas e decisões iniciais}

Visando desenvolver nos alunos habilidades de leitura e produção de gêneros orais e escritos em diversas situações de interação, respeitando as diferentes manifestações de linguagens e se adequando às diferentes circunstancias para que se consiga demonstrar competência ao fazer uso da linguagem socialmente, optamos por produzir um jogo em que se levasse em consideração gêneros de distintos domínios discursivos, com uma dinâmica que envolvesse todos os alunos em um único exemplar do jogo.

Esta opção se baseia numa carência prática: a maioria dos jogos destinados à educação contemplam um número pequeno de alunos por unidade de jogo, ficando o professor desprovido de contribuição participativa, pois se torna muito difícil gerenciar atividades com vários grupos independentes pela classe. A experiência em sala de aula nos mostra que algumas equipes se desmotivam, outras realizam atividades distintas das propostas, enquanto poucas equipes desempenham as atividades como sugeridas. Além disso, quando em uma sala de aula vários grupos estão trabalhando cada um com a sua unidade do jogo, cada equipe está situada em um universo específico, desligado das outras, dificultando a interação entre os grupos e até a organização do espaço físico da sala de aula. Portanto, o desafio inicial da elaboração do jogo foi pensar em uma dinâmica participativa que envolvesse toda a turma na mesma unidade de jogo e ao mesmo tempo, fato que pode ser considerado inovador no ambiente escolar.

Assim, acreditamos que um jogo que envolva todos os sujeitos atuantes no processo de ensino-aprendizagem, além de permitir ao professor mediar a atividade coletivamente, melhora também a interação entre os envolvidos, mantendo todos na mesma "frequência" e levando-os a construir cooperativamente conhecimentos por meio da interação entre seus pares, ensinando-os ainda o exercício da escuta, visando torná-los seguros e confiantes, e com isso ter uma maior motivação para a realização das atividades propostas.

Outra escolha do jogo foi a decisão de envolver ativamente o professor. Embora o jogo desenvolva a autonomia dos sujeitos aprendizes na tarefa de expressão linguística, acreditamos que o envolvimento do professor contribui para o desenvolvimento de um trabalho mais eficiente. Nessa perspectiva, a mediação do professor é fundamental e segundo Rojo (2010):

O professor tem uma tarefa a realizar em sala de aula e não pode ser um mero espectador do que faz o aluno ou simples facilitador do processo de aprendizagem apenas passando tarefa. Cabe a ele ensinar também e, assim, ajudar cada aluno a dar um passo adiante e progredir na construção de seus conhecimentos. (ROJO, 2010, p. 179).

Ao participar do jogo, o professor precisa encaminhar o processo com domínio e motivação, para que o aluno se engaje na atividade e se sinta corresponsável por ele. $\mathrm{O}$ professor, pois, é o mediador/gerenciador das atividades de aprender destinadas aos sujeitos no jogo.

Para se chegar até esta produção, precisávamos escolher um nome para o jogo que se adequasse ao seu propósito e estivesse de acordo com os objetivos da pesquisa. Portanto, ao elaborá-lo pensamos em um trabalho com atividades que funcionassem por meio de equipes (interação), de forma que todos os agentes envolvidos no jogo tivessem uma tarefa (ação) a 
ser realizada, que culminasse em uma produção textual oral ou escrita (linguagem). Assim, o jogo denominou-se Linguagem, Interação e Ação.

\subsection{Elementos que compõem o jogo Linguagem, Interação e Ação}

Optamos por um jogo que despertasse o interesse tanto do professor quanto do aluno. Assim, o jogo é composto pelos seguintes elementos:

- Entre 3 e 7 equipes de jogadores e mais uma equipe de avaliadores, todas com no mínimo três e no máximo cinco integrantes.

- Uma roleta com casas contendo números de 1 (um) a 10 (dez) ${ }^{3}$, que representam as esferas comercial, interpessoal, ficcional, lazer, instrucional, publicitária e a casa passe a vez e cartão coringa (para mescla de gêneros).

- 15 (quinze) cartões-comando de cada esfera, com ilustrações de um lado e cores específicas no outro, sob o texto, havendo, assim, duas simbologias a serem internalizadas pelos alunos, sendo uma em relação à ilustração, que determina a esfera de circulação, e outra em relação à cor, que determina a tipologia dominante. Nos cartões-comando é que estão as situações de produção com os desafios para cada grupo.

- Cartões-coringa: cartões que contemplam a mescla de gêneros e outras situações que poderão deixar o jogo mais dinâmico ou mais tenso. Exemplo: escolha uma equipe que passará a vez...

- Manual de orientação para o professor.

- 3 (três) placas contendo emoticons com expressões que significam: atingiu o objetivo, não atingiu o objetivo e atingiu parcialmente o objetivo proposto, para serem utilizadas pela equipe avaliadora.

- Quadro de acompanhamento do jogo. Este quadro de plástico flexível tem um tamanho aproximado de $250 \mathrm{~cm} \times 130 \mathrm{~cm}$, e será pendurado no quadro negro ou qualquer outro lugar da sala de aula. Trata-se de uma tabela que servirá para marcar o número da rodada e o sucesso ou insucesso das equipes em cada rodada, além da correspondência de simbologias.

- Um pincel para quadro branco.

\subsection{Formação das equipes}

A turma será dividida em equipes jogadoras, cada uma composta por três a cinco membros, e uma equipe avaliadora, composta por um membro de cada equipe jogadora. A equipe avaliadora ficará a cargo de coordenar o jogo, fazendo uma espécie de julgamento das atividades e anotações no quadro. O professor terá o papel de mediador e fará parte desta equipe de avaliadores, orientando e mediando as interações.

\footnotetext{
${ }^{3}$ No quadro de acompanhamento a ser fixado na lousa, encontra-se registrado o que cada número representa. Essa opção levou em conta o estímulo à atenção e o elemento unificador de equipes que o quadro de acompanhamento pode representar. Logo, os jogadores terão de ficar todos atentos ao quadro, pelo menos até a memória dispensá-lo.
} 


\subsection{Roleta}

Todo jogo é um instrumento que tende a despertar o interesse devido aos desafios que impõem aos jogadores. Mas, além do desafio, o fator sorte também costuma despertar o interesse. Ao produzir o jogo, levamos em consideração várias possibilidades de trazer este fator para a sua dinâmica, que poderia ser feita por meio da inclusão de elementos surpresa nos dados ou na roleta. Devido à quantidade limitada de faces do dado, optamos pela roleta. Por este motivo a roleta é um item muito importante para o andamento do jogo, uma vez que é por meio dela que os alunos poderão sortear a ordem em que as equipes jogarão e a esfera que será contemplada para a execução das tarefas, por exemplo.

Conforme antecipamos, a roleta é composta por dez casas numeradas de 1 (um) a 10 (dez) e cada número equivale a uma esfera de circulação (estampadas no quadro de acompanhamento). São seis casas representando as esferas de circulação, duas representando a instrução passe a vez, uma o cartão coringa (para mescla de gêneros), como dito.

\subsection{Cartões-comando}

Após o estudo sobre jogos (ALMEIDA, 2003; RAMOS, 2013; MACEDO; PETTY; PASSOS, 2005) e a análise dos jogos disponíveis no mercado, chegamos à conclusão de que um jogo que propõe desafios seria o mais apropriado para esta geração que está o tempo todo se voltando para as tecnologias, mas interagindo pouco presencialmente.

Dessa forma, entendemos que os desafios devam ser interessantes e divertidos, tanto em relação à situação proposta quanto visualmente. Durante a análise dos jogos disponíveis, a maioria dos que propõem desafios são feitos por meio de cartas que determinam um comando para se executar uma tarefa. Assim, surgiu a ideia dos cartões contendo situações para produção de textos de gêneros diversos.

Essas situações foram separadas por esferas de circulação/domínios discursivos que estão representadas em cartões próprios. Com isso, cada esfera contém um número específico de cartões com a sua ilustração, além da cor apropriada à tipologia predominante.

A ilustração no verso serve para que o aluno, ao rodar a roleta e sortear determinada esfera, tenha certeza de que aquele é o cartão referente à esfera sorteada e diante da necessidade de escolha, decidimos pela ilustração para indicar a esfera, e por cores para indicar a tipologia.

A opção feita pelo uso de uma cor específica para cada tipologia textual tem a intenção de mostrar ao aluno: primeiro, que cada gênero apresenta uma tipologia preferencial (mas não única); e, segundo, que uma mesma esfera costuma apresentar uma diversidade de gêneros e tipos textuais. Nessa perspectiva, decidimos por verde quando for para expor/relatar, amarelo para narrar, azul para argumentar, laranja para descrever e lilás quando houver sequências injuntivas.

Para isto, cada cartão contém uma situação de comunicação social que fomenta a produção de um determinado gênero textual (que pode ser oral ou escrito, formal ou informal), e que faz parte de uma esfera de circulação. Além da situação, consta no cartão uma pontuação que entre 05,10 e 20 pontos, dependendo do grau de complexidade de cada situação. $\mathrm{O}$ exemplo a seguir ilustra um cartão comando com uma das situações que constam no jogo: 
Figura 1 - Cartão da esfera comercial - gênero carta de reclamação - tipo argumentativo

O seu tão desejado smartphone chegou pelos correios. Ao ver a caixa em sua casa, a sensação de alegria foi muito grande, mas ao abri-la...que tristeza! Você percebeu que a tela estava trincada. Nossa! O que fazer? Como comprou o aparelho pela internet e não tem uma loja representante da empresa em sua cidade, você ligou para o serviço de atendimento ao consumidor e foi informado de que o aparelho estava na garantia e que seria consertado ou substituído gratuitamente. Para devolver o aparelho, por correios, no entanto, será preciso enviar uma carta de reclamação, explicando a situação e solicitando uma solução para seu problema. Então, o que vai fazer? Desistir do aparelho ou escrever uma carta de reclamação?

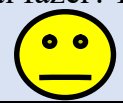

$$
0,0
$$

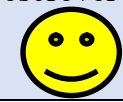

5,0

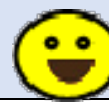

10,0

Fonte: protótipo elaborado pela pesquisa

Os cartões coringa servem para trabalharmos as mesclas de gêneros ${ }^{4}$ ou outras situações surpresas que poderão transformar a jogada em uma situação engraçada ou tensa, podendo facilitar ou dificultar o andamento do jogo. Estes cartões também têm uma determinação de tempo e de pontuação, dependendo do grau de complexidade de cada tarefa. Neles estão escritas situações como: "Escolha um cartão verde. Você terá de executar esta situação como se tivesse narrando um jogo de futebol" ou "Você tem o direito de escolher uma equipe para passar a vez".

A Fig. 2 a seguir, ilustra um cartão de cada esfera, mostrando a frente (com a imagem representativa da esfera) e o verso (com a situação de comunicação e a cor indicativa da tipologia) do protótipo produzido.

Figura 2 - Conjunto de frente e verso de cartões comado com situações de comunicações

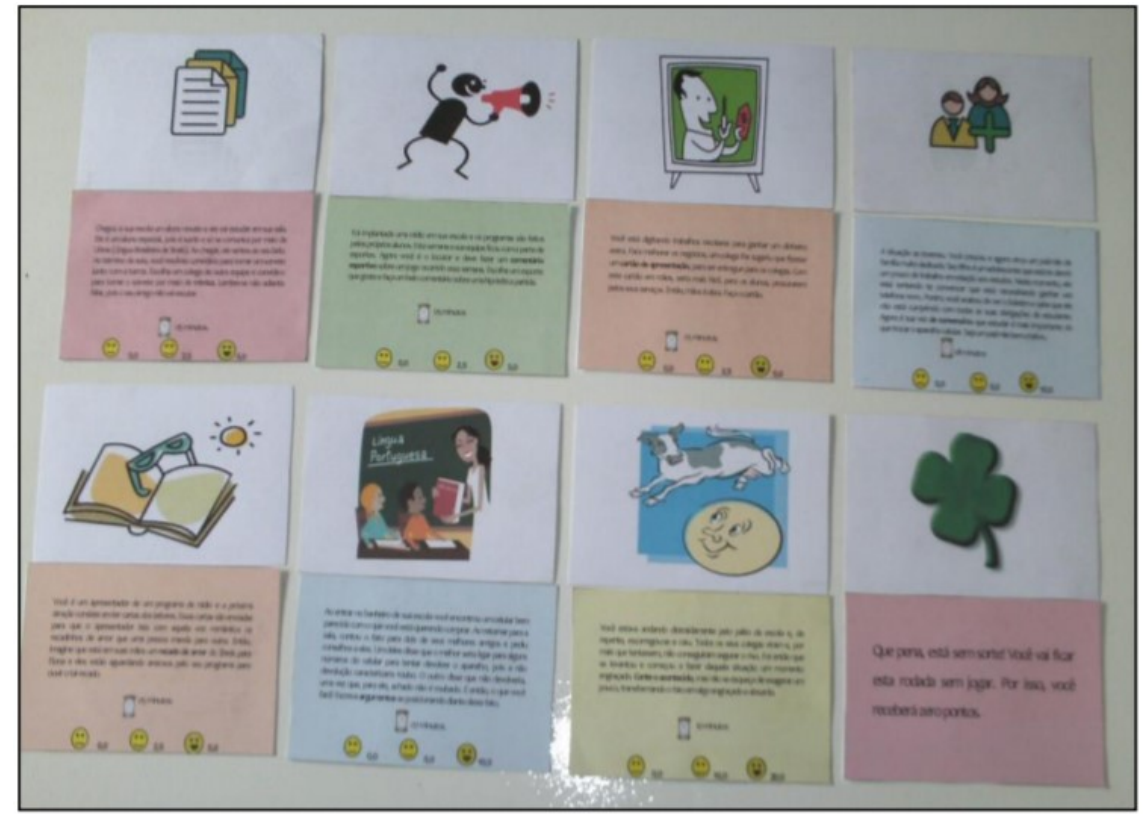

Fonte: protótipo elaborado pela pesquisa.

\footnotetext{
${ }^{4}$ Mescla de gêneros ou intergenericidade são ocasiões em que gêneros diluem suas fronteiras para fundirem-se e originarem-se outros gêneros, cuja especificidade reside na hibridização de forma e função.
} 


\subsection{Quadro de acompanhamento do jogo Linguagem, Interação e Ação}

O objetivo deste quadro é o de passar uma visão geral do andamento do jogo, unificando os jogadores, como também apresentar as informações/simbologias pertinentes a ele.

Figura 3 - Quadro de acompanhamento do jogo Linguagem, Interação e Ação

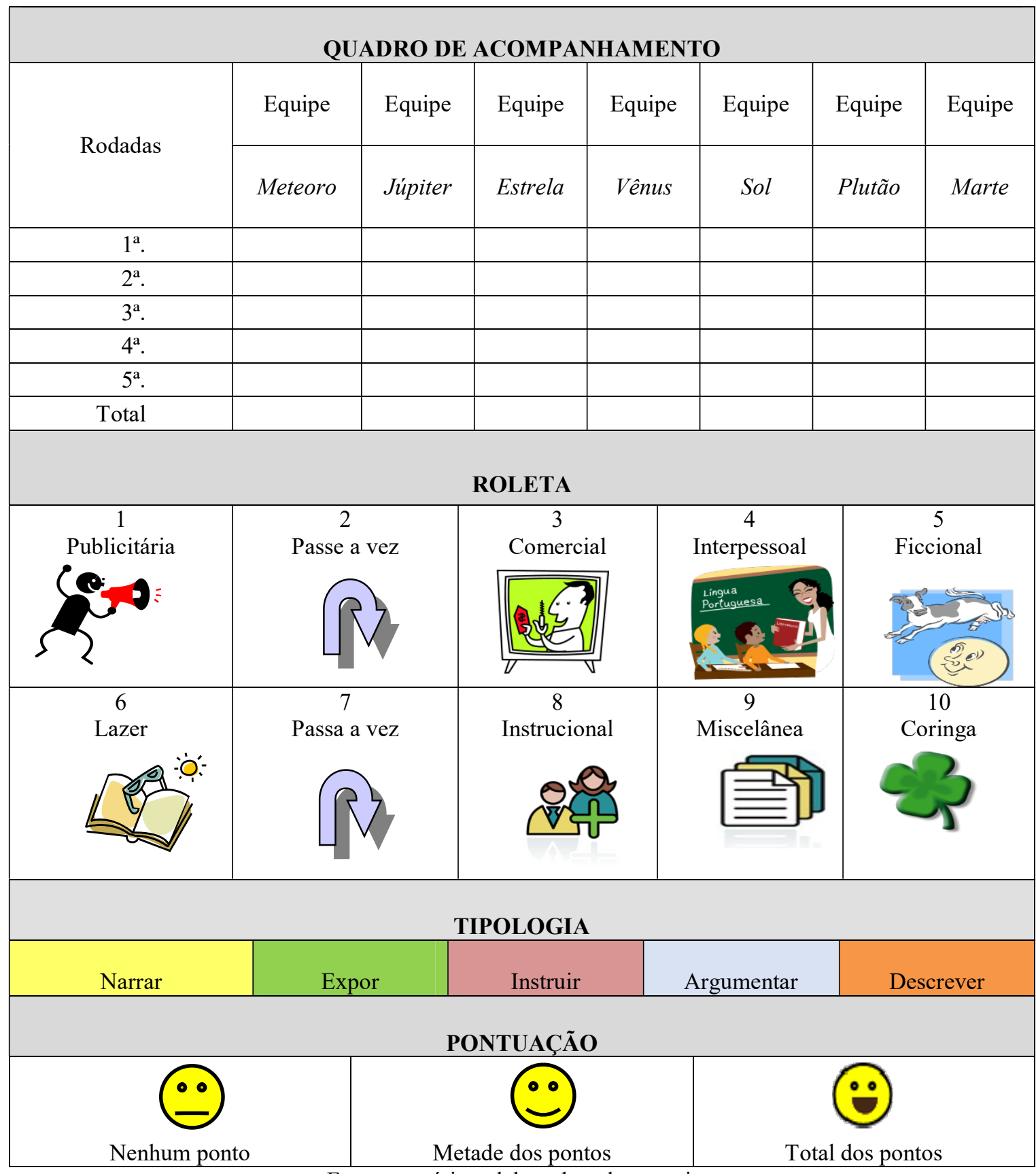

Fonte: protótipo elaborado pela pesquisa. 


\subsection{Dinâmica do jogo}

A seguir, apresentamos a dinâmica do jogo. No entanto, nada impede que o professor faça as adaptações que achar necessárias para adequá-lo à sua turma.

Para este protótipo, desenvolvemos e confeccionamos uma roleta, 130 cartões, sendo 105 (cento e cinco) cartões comando, 15 (quinze) cartões coringa e 10 (dez) cartões sorteio, um quadro de acompanhamento do jogo, três placas indicativas e um manual de instruções, como indica a imagem a seguir.

Figura 4 - Elementos que compõem o jogo: caixa, roleta, envelopes contendo cartões de comunicação e placas com emoticons.

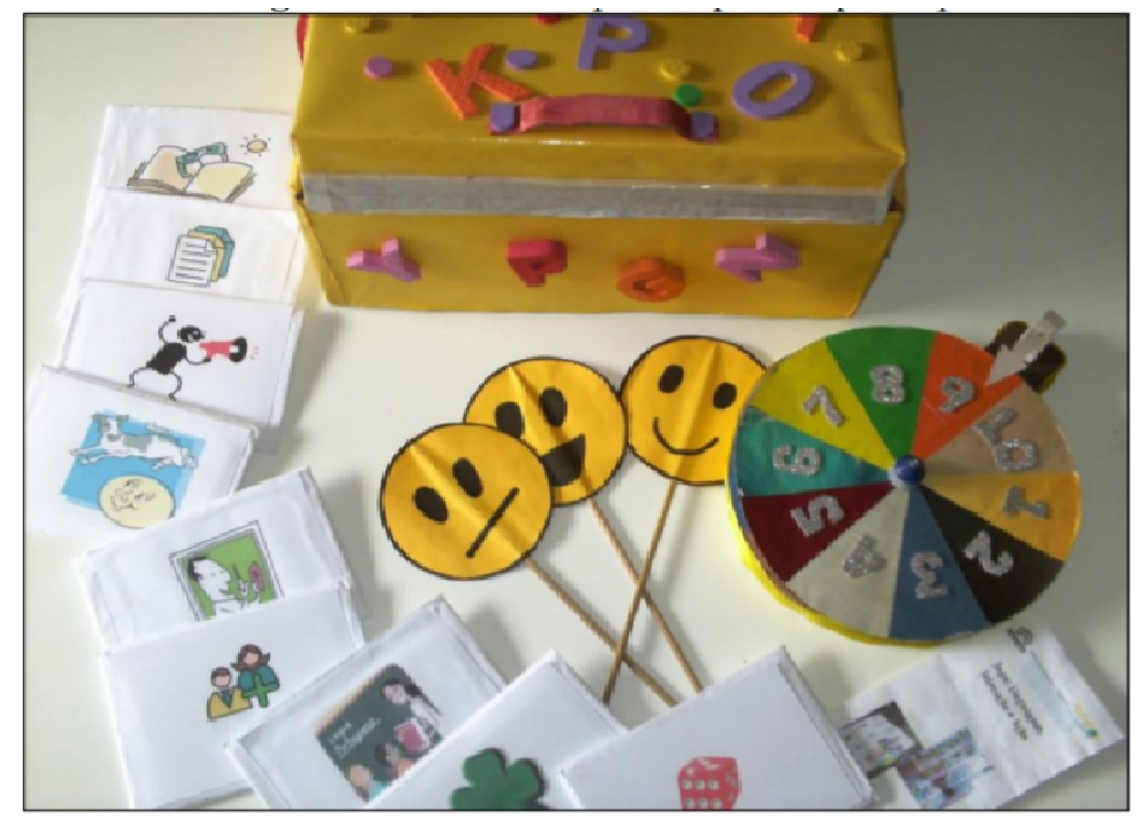

Fonte: protótipo elaborado pela pesquisa.

Como boa parte dos jogos, este também necessita de uma preparação anterior ao início da partida, assim sugerimos:

\section{a) Antes do jogo, recomenda-se:}

1. A leitura de todo o manual de instrução pelo professor, para explicitar a dinâmica do jogo e combinar regras com toda a classe;

2. Organizar a sala de aula, dividindo a turma em equipes. Caso haja um grupo maior, recomenda-se que, após o sorteio da função das equipes, um membro se desloque para a equipe de avaliadores, ou fique como auxiliar do professor-mediador. Portanto, é fundamental que as equipes jogadoras tenham o mesmo número de participantes.

3. Colocar em uma mesa separada a roleta e os cartões comando, que deverão estar separados por domínios discursivos (ou desenhos) e dispostos um abaixo do outro, com a face do desenho para cima. À medida que forem escolhidos, serão retirados do montante, para evitar que sejam escolhidos novamente; 
4. Após formar as equipes, sortear um membro de cada equipe para compor a equipe de avaliadores. Aquele que tirar o maior número em um giro de roleta, fará parte da equipe de avaliação.

5. Organizar o sorteio da ordem em que as equipes apresentarão as tarefas. Para isso, cada equipe elege um representante para rodar a roleta e aquele que tirar o número maior será a primeira equipe a apresentar a tarefa, o segundo número maior será a segunda equipe e assim sucessivamente;

6. Determinar o número de rodadas de acordo com o número de equipes, sendo o número mínimo de rodadas igual ao número total de jogadores. Exemplo: se houver três jogadores em cada equipe e alunos, o mínimo de rodadas a serem executadas deverá ser de três, para que todos os jogadores participem como apresentadores pelo menos uma vez. Com essa divisão, também ficará mais fácil para o professor interromper o jogo e recomeçar no outro dia. Nesse caso, o professor poderá determinar o número de rodadas por aula, por exemplo;

7. Organizar as equipes jogadoras e a avaliadora, de modo que tenham em mãos, pelo menos: papel para rascunho, lápis e borracha;

8. Organizar a escolha dos nomes das equipes. Estes nomes servirão para a identificação das equipes.

\section{b) Durante o jogo - regras:}

1. O professor-mediador chama um membro de cada equipe para rolar a roleta.

2. Ao girar a roleta, o membro da primeira equipe retira o cartão (mas não o lê) e aguarda até que o membro da última equipe faça o mesmo;

3. Ao término do sorteio de todas as equipes, os representantes voltam para suas equipes e apresentam o cartão à equipe, que começará a discutir a realização da atividade por um tempo igual ou inferior a 10 (dez) minutos;

4. Mesmo que algum grupo termine antes do tempo, ele terá que aguardar o término do tempo determinado e respeitar a ordem de apresentação;

5. Durante todo o jogo, cada equipe poderá pedir a extensão do tempo, por até cinco minutos, apenas uma vez, neste caso, o tempo se estende a todas as equipes;

6. Durante o jogo, as equipes poderão realizar perguntas ao professor-mediador, quando necessário;

7. O professor-mediador deverá orientar todas as equipes quanto ao término do tempo, ou determinar que um aluno o faça (a critério do professor-mediador);

8. O professor-mediador poderá percorrer a sala fazendo uma pequena "varredura ortográfica ${ }^{5}$ " nos textos de todas as equipes;

9. Após o término do tempo, os grupos deverão verbalizar as situações sorteadas e a atividade desenvolvida, obedecendo a ordem do sorteio;

10. Após a apresentação de cada grupo, a equipe avaliadora irá fazer a análise da apresentação da situação e levantará a placa indicativa referente ao julgamento feito. Caso a equipe julgadora chegue ao resultado de que o grupo não atingiu o objetivo proposto, ou que o atingiu parcialmente, ela deverá se justificar oralmente;

11. O professor-mediador, então, irá anotar no quadro de acompanhamento o valor alcançado pela equipe, que estará escrito no cartão sorteado por ela, ou determinar que um aluno o faça (à critério do professor-mediador);

\footnotetext{
${ }^{5}$ Entende-se por varredura ortográfica uma análise rápida dos textos, durante a sua produção para análise de erros considerados gritantes ou recorrentes.
} 
12. O término da rodada acontecerá após a apresentação e o julgamento de todas as equipes, a partir daí, o professor-mediador poderá convocar os representantes das equipes para o sorteio da próxima rodada;

13. Se na última rodada tiver mais de uma equipe com a mesma pontuação, ambas deverão fazer uma tarefa de desempate. A tarefa de desempate será sorteada e avaliada unicamente pelo professor-mediador. As duas equipes executarão a mesma tarefa e sairá vencedora aquela que produzir o texto mais adequado à situação de comunicação descrita.

\section{Observações:}

- Ganhará o jogo a equipe que fizer mais pontos após o término de todas as rodadas determinadas pelo mediador;

- O jogo poderá ser interrompido e reiniciado após cada rodada, para que possa ser adaptado à carga horária escolar;

- Sugere-se que o professor-mediador incentive a participação da turma, por meio de alguma premiação para a equipe ganhadora e para a equipe avaliadora (poder ser 1 ponto ou cinco minutos a mais de intervalo, por exemplo);

- O quadro de acompanhamento é uma sugestão. Se o número de equipes for superior à quantidade prevista no quadro, o professor-mediador (ou quem ele determinar) poderá fazer as anotações referentes a pontuação no quadro negro/branco, ou outro local que seja visível para todas as equipes.

\section{Considerações finais}

Esta pesquisa objetivou produzir um jogo de linguagem alicerçado nas funções sociais de gêneros textuais, para ser utilizado em sala de aula do Ensino Fundamental como ferramenta didática que visa envolver os alunos em um ambiente de ludicidade que favoreça tanto a produção quanto a compreensão de gêneros, de modo a permitir que os alunos construam cooperativamente conhecimentos entre seus pares.

A escolha por um jogo de linguagem foi atribuída à constatação de que a prática de produção de texto, no Ensino Fundamental, é, em grande medida, mecânica, artificial e dominada sempre pelos mesmos gêneros, fato que causa apatia e desinteresse nos alunos, além de, consequentemente, baixo desempenho em atividades de expressão.

Visando abrir espaços para os jogos de linguagem como instrumentos de ensino de língua materna, a pesquisa privilegiou a interação entre os alunos em eventos comunicativos diversos, dentro de um ambiente escolar motivador e integrado às atividades de expressão cotidianas, de modo a levar os alunos a reconhecerem o uso social da escrita, permitindo que aprendam a escrever de forma divertida.

Acreditamos que uma proposta de ensino-aprendizagem, por meio de um jogo didático, organizada a partir de gêneros, permite ao professor a observação e a avaliação das capacidades de linguagem dos alunos antes e durante sua realização, assim, poderá fornecer orientações mais precisas para sua intervenção didática. Para os alunos, este recurso didático constitui uma forma de se confrontarem com situações sociais efetivas de produção de textos diversos, objetivando uma maneira de operá-los com mais eficácia e progressivamente. 


\section{Referências}

ALMEIDA, P. N. de. Educação lúdica: técnicas e jogos pedagógicos. 11 ed. São Paulo: Edições Loyola, 2003.

ALMEIDA, P. N. de. Língua portuguesa e ludicidade: ensinar brincando não é brincar de ensinar. 2007. 130f. Dissertação (Mestrado em Língua Portuguesa) - Pontifícia Universidade Católica de São Paulo, São Paulo. 2007. Disponível em: https://sapientia.pucsp.br/handle/handle/14465. Acesso em: 16 nov. 2013.

BAKHTIN, M. Estética da criação verbal. Martins Fontes: São Paulo, 2003.

DOLZ, J.; GAGNON, R.; DECÂNDIO, F. Produção escrita e dificuldades de aprendizagem. Campinas: Mercado das Letras, 2010.

KISHIMOTO, T. M. O jogo e a educação infantil. São Paulo: Fronteira, 1998.

MACEDO, L; PETTY, A. L. S.; PASSOS, N. C. Os jogos e o lúdico na aprendizagem escolar. Porto Alegre: Artmed, 2005.

MARCUSCHI, L. A. Produção textual, análise de gêneros e compreensão. São Paulo: Parábola Editorial, 2008.

RAMOS, D. K. Jogos cognitivos eletrônicos: contribuições à aprendizagem no contexto escolar. Ciências e cognição. v. 18, p. 19-32, 2013. Disponível em: www.cienciaecognicao.org. Acesso em 22 abr. 2014.

ROJO, R. Ação e mudança na sala de aula: uma pesquisa sobre letramento e interação. In: Letras, 1998. . (Org.). Alfabetização e letramento: perspectivas linguísticas. Campinas: Mercado das

SCHNEUWLY, B.; DOLZ, J. Gêneros orais e escritos na escola. Campinas: Mercado de Letras, 2004.

Recebido em: julho de 2017.

Aprovado em: agosto de 2017. 